\title{
Estimating incident impacts on urban street travel time in the case of super saturation in traffic lights
}

\section{Estimación de impactos de incidentes en el tiempo de viaje en la calle urbana en el caso de super saturación en las luces de traffic}

\author{
Hooman Rahimi ${ }^{1}$, Hasan Zoghi $^{2}$, Saeed Monajem ${ }^{3}$ \\ 1. School of Civil Engineering, Central Tehran Branch, Islamic Azad University, Tehran, Iran \\ 2. Department of Civil Engineering College of Technical and Engineering \\ Karaj Branch, Islamic Azad University, Alborz, Iran \\ ${ }^{3}$ Department of Civil Engineering College of Technical and Engineering, \\ Central Tehran Branch, Islamic Azad University, Tehran, Iran
}

(recibido/received: 05-April-2020; aceptado/accepted: 13-July-2020)

\begin{abstract}
Dynamic signal control strategies are effective in relieving congestions during nontypical days, such as those with high demands, incidents with different attributes, and adverse weather conditions. This research recognizes the need to model the impacts of dynamic signal controls for different days representing, different demand and incident levels. Methods are identified to calibrate the utilized tools for the patterns during different days based on demands and incident conditions utilizing combinations of real-world data with different levels of details. A significant challenge addressed in this study is to ensure that the mesoscopic simulation-based dynamic traffic assignment (DTA) models produces turning movement volumes at signalized intersections with sufficient accuracy for the purpose of the analysis. A new model is developed to estimate the drop in capacity at the incident location by considering the downstream signal control queue spillback effects. The developed capacity reduction models were used to estimate delay due to an urban street incident. The delay was calculated as a combination of the delay due to queuing on the incident link and the increase in upstream intersection control delays due the reduction in maximum throughputs resulting from queue spillback to the upstream intersection The HCS-based method estimated a reduction in delay resulting from the new signal timing plan to be around 3,404 vehicle-hours, whereas the VISSIM shows that the new signal timing saving in delay is 4,008 vehicle-hours. This confirms that the developed method and VISSIM estimation of the benefits are consistent.
\end{abstract}

Keywords: Impact, Urban, Travel Time,Traffic, Traffic light

\section{RESUMEN}

Las estrategias de control dinámico de la señal son efectivas para aliviar las congestiones durante los días no típicos, como aquellos con altas demandas, incidentes con diferentes atributos y condiciones climáticas adversas. Esta investigación reconoce la necesidad de modelar los impactos de los controles de señales dinámicas para diferentes días que representan diferentes niveles de demanda e incidentes. Los métodos se identifican para calibrar las herramientas utilizadas para los patrones durante diferentes 
días en función de las demandas y las condiciones del incidente utilizando combinaciones de datos del mundo real con diferentes niveles de detalles. Un desafío importante abordado en este estudio es garantizar que los modelos de asignación dinámica de tráfico (DTA) basados en simulación mesoscópica produzcan volúmenes de movimiento de giro en intersecciones señalizadas con suficiente precisión para el propósito del análisis. Se desarrolla un nuevo modelo para estimar la caída de la capacidad en la ubicación del incidente considerando los efectos de derrame de la cola de control de señal aguas abajo. Los modelos de reducción de capacidad desarrollados se utilizaron para estimar el retraso debido a un incidente en una calle urbana. El retraso se calculó como una combinación del retraso debido a las colas en el enlace incidente y el aumento de los retrasos en el control de la intersección aguas arriba debido a la reducción en los rendimientos máximos resultantes del derrame de la cola a la intersección aguas arriba El método basado en HCS estimó una reducción en el retraso resultante del nuevo plan de temporización de la señal será de alrededor de 3.404 horas de vehículo, mientras que el VISSIM muestra que el nuevo ahorro de temporización de la señal con retraso es de 4.008 horas de vehículo. Esto confirma que el método desarrollado y la estimación VISSIM de los beneficios son consistentes.

Palabras clave: Impacto, Urbano, Tiempo de viaje, Tráfico, Semáforo

\section{INTRODUCCIÓN}

Assessing the impacts of incident management strategies on performance measures allows traffic management agencies to prioritize their investment in these strategies by supporting better planning for operations and operator decisions. There has been an increasing interest in analyzing the impacts of incident management performance on urban streets. The reduction of the impacts of incidents by applying incident management and signal control strategies is one of the main interests of transportation agencies.

The impacts of incident and incident management on mobility measures have been

widely investigated for freeway facilities. Four methods have been used by transportation agencies for the following: empirical analysis, queuing analysis, shock wave analysis, and simulation modeling. Queuing and shockwave analysis methods have been successfully applied to the estimation of incident and bottleneck delays on freeway facilities (Zhang et al., 2010; Hong et al., 2013) (Hadi et al., 2007). As discussed in the literature review, these methods may not be accurate in terms of estimating delays for incidents on signalized urban streets without the consideration of the interactions between traffic signal operations and the capacity drop at the incident location.

Traffic simulation has also been used to estimate incidents and incident management impacts (Gomes et al., 2004; Crowe 2009). Such analysis is able to model the interactions between the drops in capacity due to incidents and intersection operations.

However, the use of simulation models can be costly in terms of data collection, model input preparation, and calibration, especially when the incident management strategies need to be evaluated at the regional levels when the stochastic nature of incident features and locations need to be considered in the analysis, and when the incident impact has to be analysed for a long period of time (e.g., one year), and for real-time operations.

This article discusses the development and application of a method to estimate such impacts of support of planning for operations and operational processes. This chapter first discusses the extension of existing analytical procedures to allow better assessment of the impacts of incidents considering the interactions between the reductions in capacity below demands at midblock urban street segment locations and upstream and downstream signalized intersection operations, as explained in the previous chapter. This chapter also discusses the incorporation of the method in a data analytical tool and its use to inform the identification of a special signal timing plan to reduce incident impacts as part of a decision support system. 
interactions between the drops in capacity due to incidents and intersection operations.

However, the use of simulation models can be costly in terms of data collection, model input preparation, and calibration, especially when the incident management strategies need to be evaluated at the regional levels when the stochastic nature of incident features and locations need to be considered in the analysis, and when the incident impact has to be analysed for a long period of time (e.g., one year), and for real-time operations.

This article discusses the development and application of a method to estimate such impacts of support of planning for operations and operational processes. This chapter first discusses the extension of existing analytical procedures to allow better assessment of the impacts of incidents considering the interactions between the reductions in capacity below demands at midblock urban street segment locations and upstream and downstream signalized intersection operations, as explained in the previous chapter. This chapter also discusses the incorporation of the method in a data analytical tool and its use to inform the identification of a special signal timing plan to reduce incident impacts as part of a decision support system.

\section{METHODOLOGY}

The first step was the data acquisition. Data from multiple sources and agencies was collected and processed to develop and calibrate models. Next, acombination of tools were selected for the modeling and analysis of this research. After the tool selection, the next step was network preparation for modeling. The network geometry was imported, updated, and cleaned to better represent the existing real-world network. Different traffic patterns were identified for modeling to represent different demands and congestion levels. Then, the traffic network and demand parameters (supply and demand) of the simulation-based DTA models were calibrated for different demand levels utilizingreal-world measures such as traffic flow, on each link and on each turning movement. The trip matrices were estimated for 15 minutes' time intervals for input to the DTA models. An Origin Destination Matrix Estimation (ODME) process was implemented through three levels of calibration. In the first level (the network level), the overall network was calibrated. Since the arterial streets are the focus of this study, in the second level, a more detailed calibration of the demands on arterial street segments was conducted. In the third level, the demands of the intersections' turning movements were calibrated through a focus calibration on these movements. The next steps in the model preparation for modeling was to prepare the microscopic simulation model network. The calibrated model was imported from the simulation-based DTA tool to the microscopic tool. The combination of the two tools allowed the assessment of the traffic and incident responsive signal control.

\section{RESEARCH BACKGROUND}

ATDM strategies dynamically control and manage traffic demand, travel demand, and traffic flow of transportation facilities (1, 2) (Sheehban et al., 2012; Khazraeian et al., 2015). The Federal Highway Administration's (FHWA) ATDM programs was introduced to support active, integrated and performancebased solutions to enhance safety, maximize system productivity, and improve individual mobility in multimodal surface transportation systems. Examples of ATDM strategies are shown in Table 1 (Mohammed Hadi et al., 2016).

Table 1. Examples of ATDM Strategies

\begin{tabular}{|l|l|l|}
\hline $\begin{array}{l}\text { Active Traffic } \\
\text { Management (ATM) }\end{array}$ & $\begin{array}{l}\text { Active Demand } \\
\text { Management (ADM) }\end{array}$ & $\begin{array}{l}\text { Active Parking } \\
\text { Management (APM) }\end{array}$ \\
\hline Adaptive Ramp Metering & Dynamic Fare reduction & $\begin{array}{l}\text { Dynamic Overflow } \\
\text { Transit Parking }\end{array}$ \\
\hline $\begin{array}{l}\text { Adaptive Traffic Signal } \\
\text { Control }\end{array}$ & $\begin{array}{l}\text { Dynamic HOV/Managed } \\
\text { Lanes }\end{array}$ & $\begin{array}{l}\text { Dynamic Parking } \\
\text { Reservation }\end{array}$ \\
\hline
\end{tabular}




\begin{tabular}{|l|l|l|}
\hline Dynamic Junction Control & Dynamic Pricing & Dynamic Wayfinding \\
\hline $\begin{array}{l}\text { Dynamic Lane Reversal or } \\
\text { Contraflow Lane Reversal }\end{array}$ & Dynamic Ridesharing & Dynamic Priced Parking \\
\hline Dynamic Lane Use Control & Dynamic Routing & \\
\hline Dynamic Merger Control & $\begin{array}{l}\text { Dynamic Transit Capacity } \\
\text { Assignment }\end{array}$ & \\
\hline Dynamic Shoulder Lanes & On-Demand Transit & \\
\hline Dynamic Speed Limits & $\begin{array}{l}\text { Predictive Traveler } \\
\text { Information }\end{array}$ & \\
\hline Queue Warning & $\begin{array}{l}\text { Transfer Connection } \\
\text { Protection }\end{array}$ & \\
\hline Transit Signal Priority & & \\
\hline
\end{tabular}

\section{RESEARCH FINDINGS}

Incident management is a vital part of ATM strategies. Estimating the impact of incidents and incident management allows traffic management agencies to determine the need for various incident management strategies and technologies to justify the decision to invest in their programs. This research describes a new approach to estimate the capacity impacts due to arterial incidents that result from the interaction between the drop in capacity below demands at midblock urban street segment locations and upstream and downstream signalized intersection operations. This research also describes the development and application of a new model that can estimate the impacts of incidents and incident management strategies on urban street facilities. The developed method was successfully used to estimate the impact of modifying signal timing plans during incidents with consideration of the estimating drop in capacity.

\subsection{Estimating Incident Impact on Delay}

This study develops a method to estimate incident delay using a combination of the delay due to queuing on the mid-block incident link and the increase in upstream intersections delay due to the reduction of the saturation flow rate or maximum throughput resulting from the queue spillback at the upstream intersection. The first component was calculated using deterministic queueing analysis equations, as is used in estimating incident delays on freeways. This method estimates the total delays based on incident duration, mean arrival rate (demand), and mean capacity under incident condition. The total delay due to lane blockage is calculated, as follows: (May, 2016).

$$
\begin{gathered}
\mathrm{TD}=(\mathrm{tR})(\mathrm{tQ})(\lambda-\mu R) / 2 \\
\mathrm{tq}=(\mathrm{tR})(\mu-\mu R) /(\mu-\lambda)
\end{gathered}
$$

$\mathrm{TD}=$ total delay,

$\mathrm{tQ}=$ average time in queue,

$\mu=$ mean capacity under normal conditions,

$\mu \mathrm{R}=$ mean capacity under incident conditions,

$\lambda=$ mean arrival rate, and

$\mathrm{tR}=$ average incident duration.

The increase in the upstream intersection delay is calculated using the signalized intersection control delay method presented in the 2010 version of the Highway Capacity Manual (HCM 2010) (TRB Manual, 2010). The method calculates control delay as the sum of three components: uniform, incremental, and initial queue delays. An important parameter for calculating delay using this method is the capacity of the assessed lane group, which is normally calculated as the multiplication of the saturation flow rate and the effective green time divided by cycle length. To account for the spillback from the incident location, this study estimates upstream intersection capacity utilizing regression models as a function of incident attributes, volume-tocapacity ratio at the incident location, and upstream signal timing, as described in the next section. 


\subsection{Capacity of Urban Street Segments}

As mentioned earlier, the saturation flow adjustment factor is a function of the number of lanes, number of lanes blocked by the incident, and coefficients related to incident severity. However, the adjustment factor does not address incident locations other than at the stop line. These incidents are expected to impact the signal operations. An incident occurring at a mid-block location can decrease the throughput of the incident link. If the queue from the incident spills back to the upstream link, it will decrease the upstream intersection throughput and consequently, the operations.

the reduction in the upstream intersection throughputs in the analysis period, which is a function of how far the incident is from the upstream intersection, the volume to capacity (v/Ic) ratio at the incident location, the incident

duration, and the upstream intersection signal timing. The capacity at the incident location (Ic) is also affected by downstream intersection parameters, including how far the incident is from the downstream intersection, and also discusses the green to cycle-length $(\mathrm{g} / \mathrm{C})$ ratio and number of total and blocked lanes. Therefore, the developed regression models estimate upstream and downstream link capacities during incidents based on incident characteristics, upstream signal operations, and downstream signal operations. The first model estimates the lane-blockage capacity at the incident location with consideration of the impacts of the downstream signal queue spill back at different incident locations from the downstream signal. The second model estimates the reduction in the upstream intersection throughput due to incidents at different downstream locations. Both models can be used together to estimate capacities during incident conditions that can be used as inputs to the analytical delay equations described in the previous section. The developed models to estimate downstream (incident) link capacity and upstream intersection throughput are summarized and shown in Table 1.

Table 1 Regression Models to Estimate Interaction Between the Drop in Capacity due to Incidents and Upstream and Downstream Signal Operations

\begin{tabular}{|c|c|c|c|}
\hline $\begin{array}{c}\text { Number of } \\
\text { Lane Blockage }\end{array}$ & $\begin{array}{l}\text { Downstream } \\
\text { Signal g/C }\end{array}$ & Upstream Incident Capacity & $\mathrm{R} 2$ \\
\hline One Lane & 0.67 & $\mathrm{IC}=0.624 \mathrm{x}+532$ & 0.921 \\
\hline Blockage & 0.55 & $\mathrm{IC}=0.5922 \mathrm{x}+646.23$ & 0.902 \\
\hline Two Lane & 0.67 & $\mathrm{IC}=6 \mathrm{E}^{-07} \mathrm{x} 3-0.0015 \mathrm{x} 2+1.1292 \mathrm{x}+192.34$ & 0.891 \\
\hline Blockage & 0.55 & $\mathrm{IC}=4 \mathrm{E}^{-07} \mathrm{x} 3-0.0011 \mathrm{x} 2+0.839 \mathrm{x}+212.18$ & 0.908 \\
\hline $\begin{array}{l}\text { Incident } \\
\text { Duration }\end{array}$ & $\begin{array}{l}\mathrm{v} / \mathrm{Ic} \text { at Incident } \\
\text { Location }\end{array}$ & Intersection Maximum Throughput & $\mathrm{R} 2$ \\
\hline \multirow{3}{*}{$\begin{array}{c}15 \\
\text { Minutes }\end{array}$} & 1.13 & $\mathrm{SF}=0.4765 \times 1+1023.6$ & 0.822 \\
\hline & 1.15 & $\mathrm{SF}=0.3217 \times 1+1087.7$ & 0.816 \\
\hline & 1.50 & $\mathrm{SF}=0.3254 \mathrm{x} 1+854.31$ & 0.793 \\
\hline \multirow{3}{*}{$\begin{array}{c}35 \\
\text { Minutes }\end{array}$} & 1.13 & $\mathrm{SF}=0.4512 \mathrm{x} 1+1013.7$ & 0.744 \\
\hline & 1.15 & $\mathrm{SF}=0.3112 \mathrm{x} 1+998$ & 0.794 \\
\hline & 1,50 & $\mathrm{SF}=0.2342 \times 1+843.35$ & 0.789 \\
\hline \multirow{3}{*}{$\begin{array}{c}45 \\
\text { Minutes }\end{array}$} & 1.13 & $\mathrm{SF}=0.4179 \mathrm{x} 1+1002.4$ & 0.765 \\
\hline & 1.15 & $\mathrm{SF}=0.3112 \times 1+892.88$ & 0.654 \\
\hline & 1.50 & $S F=0.1998 x+897.82$ & 0.637 \\
\hline
\end{tabular}




\subsection{Arterial Delay Estimation Accuracy Assessment Results}

In the developed model, incident delays were estimated as the sum of the incident link delays based on the queuing equations and the increase in upstream control delay due to spillback with consideration of the drop in saturation flow rates due to the incident according to the developed regression models in Table 7-1. The Highway Capacity Software (HCS) was used for the calculation of the control delay with the adjusted saturation flow rates as shown in Table 1 . The resulting arterial incident delay was evaluated by comparing the results with incident delays estimated using VISSIM. The VISSIM model accounts for the effects of the interactions between upstream and downstream signal operations and midblock incident capacity drops since it models the queue spillbacks between different segments in the network. The scenario used in this comparison involves a midblock incident that results in a demand to capacity ratio of 1.13 at the incident location. Incidents at different locations were modeled in VISSIM (calibration of the VISSIM network explained in the previous chapter), and the additional delays due to the incidents were extracted based on the average of ten runs for the noincident conditions and ten runs for the incident conditions.

The network coded in the HCS was matched with the VISSIM network to provide a valid comparison. The calibrated VISSIM model with no incidents produced a saturation flow rate of $1799 \mathrm{veh} / \mathrm{hr} / \mathrm{lane}$, which was used as the input saturation flow rate in the HCS analysis. The base analysis period in the HCM, and thus HCS analysis, is fixed at 15 minutes. The simulated incident duration in this study is 35 minutes. Therefore, during the incident condition, the saturation flow rates within the first two periods (30 minutes) were calculated based on the regression equations presented in Table 1. For the third period (between 30 and 45 minutes), after the incident occurrence, in order to account for the additional 5 minutes of the incident duration, the saturation flow was calculated as a weighted average of the saturation rate during the incident in the first 5 minutes of the period and the no-incident saturation flow rate during the last 10 minutes of the period. This accounted for the full 35-minute period of the incident. The incident delays in the HCS and VISSIM were calculated as the difference between the delay with incident and without incident. A comparison was also made of the estimation of the incident delay using the queuing equation by itself to determine the delay at the midblock incident location, as has been used for freeway incidents. The incident delay comparison results are shown in Figure 1.

Figure 1 shows that the incident delay decreased by moving the incident from the upstream signal toward the downstream, which is expected due to the reduction in the impact on the upstream intersection throughputs due to queue spillbacks. The results show that the use of the combination of deterministic queuing and the HCM equations procedure with the modified saturation flow of Table 1 to calculate incident delays produced results that are closer to the delays estimated by the microsimulation models, compared to the results obtained based on the deterministic queuing procedure by itself. This is particularly true for incidents located at closer distances (up to 120$150 \mathrm{~m}$ ) from the upstream intersection for the v/Ic ratio of this scenario, which is 1.13 . Beyond this point, the VISSIM simulation shows higher impacts oincidents on the delay of the upstream intersection,compared to the HCM procedure, even with the modified saturation flow rates. 


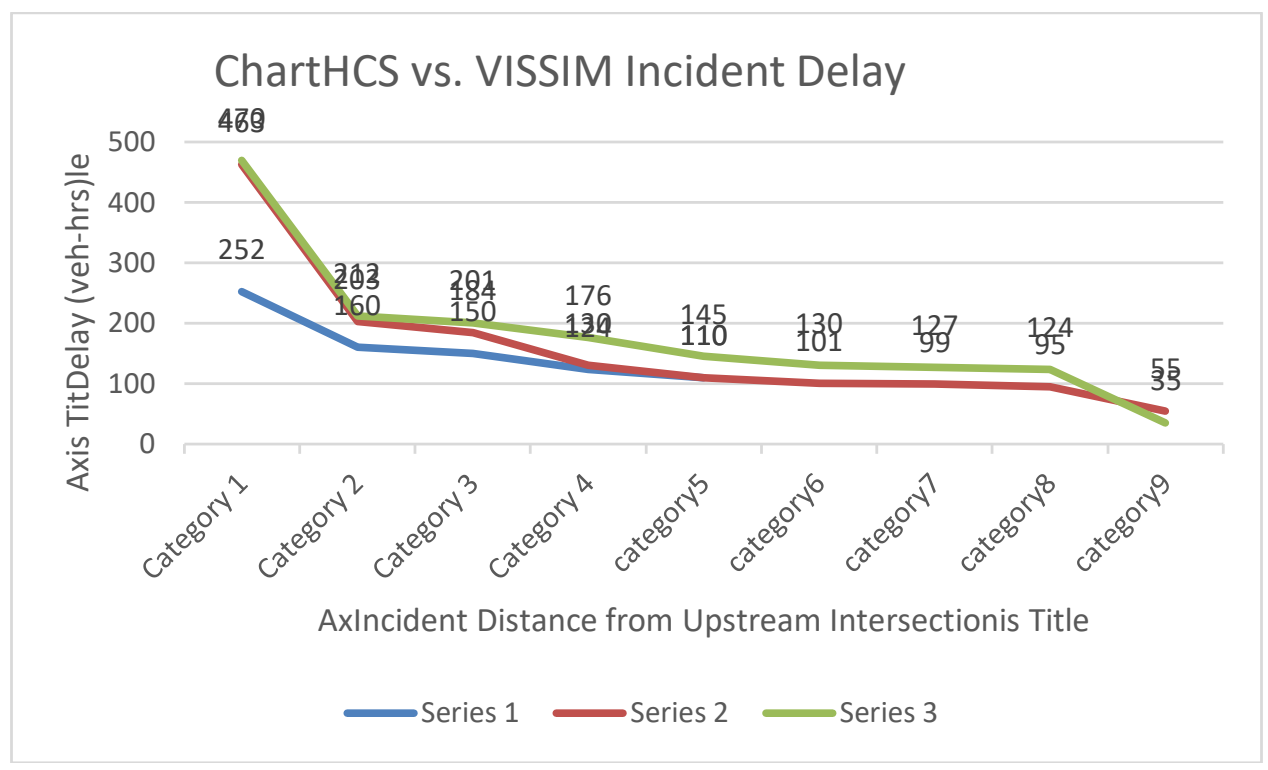

This may be due to the stochastic nature of VISSIM, which better reflects the randomness of traffic arrivals and dissipations. The HCM procedures do notfully accountfor this randomness, and thus it may underestimate the impacts under certain conditions.

\subsection{Assessing the impacts of downstream signal on upstream incident capacity}

Based on the simulation results for one lane blockage, the upstream incident capacity was not found to be affected by the downstream intersection when the incidents occur at $400 . \mathrm{m}$ and $433 . \mathrm{m}$. from the downstream signal and when the $\mathrm{g} / \mathrm{C}$ ratio at the downstream signal equals 0.67 and 0.55 , respectively. These values were selected for use in the analysis based on typical $\mathrm{g} / \mathrm{C}$ ratios for the main street in the analysis area. Reducing the $\mathrm{g} / \mathrm{C}$ ratio to a level that constrains the departing volumes from the upstream link is expected to reduce the traffic volume arriving at the downstream incident location, and this may reduce the portion of unconstrained green. For the two-lane blockage incident, the capacity at the incident location was not affected significantly by the downstream intersection when the incident occurs at $75 \mathrm{~m}$. or more from the downstream signal. This distance is the same for both $\mathrm{g} / \mathrm{C}$ ratios $(0.55$ and 0.67$)$.

The data presented was used to develop regression models to estimate the incident capacity (IC) based on the investigated influencing factors. The developed regression models are presented in Table 2. The developed regression models show that there is a significant relationship between the incident capacity and the three independent variables, mentioned earlier, as indicated by the Coefficient of Determination (R-Squared) values and the t-test of the significance of the independent variable coefficients. If the $\mathrm{g} / \mathrm{C}$ ratio for an assessed condition is between the two $\mathrm{g} / \mathrm{C}$ ratios assessed in this study, as displayed in Table2, interpolation can be used to estimate the capacity. 
Table 2. Upstream interrupted incident capacity regression models

\begin{tabular}{|c|c|c|c|}
\hline $\begin{array}{c}\text { Number of } \\
\text { Lane Blockage }\end{array}$ & $\begin{array}{c}\text { Downstream } \\
\text { Signal g/C }\end{array}$ & Upstream Incident Capacity & $\mathrm{R} 2$ \\
\hline One Lane & 0.67 & $\mathrm{IC}=0.624 \mathrm{x}+532$ & 0.921 \\
\hline Blockage & 0.55 & $\mathrm{IC}=0.5922 \mathrm{x}+646.23$ & 0.902 \\
\hline Two Lane & 0.67 & $\mathrm{IC}=6 \mathrm{E}^{-07} \mathrm{x} 3-0.0015 \mathrm{x} 2+1.1292 \mathrm{x}+192.34$ & 0.891 \\
\hline Blockage & 0.55 & $\mathrm{IC}=4 \mathrm{E}^{-07} \mathrm{x} 3-0.0011 \mathrm{x} 2+0.839 \mathrm{x}+212.18$ & 0.908 \\
\hline $\begin{array}{l}\text { Incident } \\
\text { Duration }\end{array}$ & $\begin{array}{l}\text { v/Ic at Incident } \\
\text { Location }\end{array}$ & Intersection Maximum Throughput & R2 \\
\hline \multirow{3}{*}{$\begin{array}{c}15 \\
\text { Minutes }\end{array}$} & 1.13 & $\mathrm{SF}=0.4765 \times 1+1023.6$ & 0.822 \\
\hline & 1.15 & $\mathrm{SF}=0.3217 \times 1+1087.7$ & 0.816 \\
\hline & 1.50 & $\mathrm{SF}=0.3254 \times 1+854.31$ & 0.793 \\
\hline \multirow{3}{*}{$\begin{array}{c}35 \\
\text { Minutes }\end{array}$} & 1.13 & $\mathrm{SF}=0.4512 \mathrm{x} 1+1013.7$ & 0.744 \\
\hline & 1.15 & $\mathrm{SF}=0.3112 \times 1+998$ & 0.794 \\
\hline & 1,50 & $\mathrm{SF}=0.2342 \mathrm{x} 1+843.35$ & 0.789 \\
\hline \multirow{3}{*}{$\begin{array}{c}45 \\
\text { Minutes }\end{array}$} & 1.13 & $\mathrm{SF}=0.4179 \mathrm{x} 1+1002.4$ & 0.765 \\
\hline & 1.15 & $\mathrm{SF}=0.3112 \mathrm{x} 1+892.88$ & 0.654 \\
\hline & 1.50 & $S F=0.1998 x+897.82$ & 0.637 \\
\hline
\end{tabular}

\subsection{Model Utilization for Decision Support}

As stated earlier, transportation agencies are interested in assessing the impacts of various strategies to reduce incident impacts on signalized urban arterials, including the application of special signal plans during incidents. Currently, this can only be achieved by utilizing simulation models that consider the interaction between the operations at the incident location and upstream and downstream signals. The model developed in this study can be used to support analytical assessments of such strategies by incorporating the impacts of such interactions.

Recognizing the need discussed above, the method developed in this study has been implemented in a web-based data analytics tool, referred to as the ITS Data Capture and Performance Management tool, which was developed for the Tehran of Transportation by a research team. ITS is a data analytics tool that has a number of modules for utilizing real-time and archived data to support agency operations. The implemented method in ITS allows the user to better estimate of the impacts of incidents on urban arterials and potential strategies such as incident management activities that reduce the lane blockage duration and the implementation of a signal timing plan in response to incident conditions. To illustrate the utilization of the ITS implementation, the methodology was applied to a real-world case study of an incident that occurred at west tirandaz and east resalat interchange. The incident location was 0.1 mile from the upstream signal and 0.25 mile from the downstream signal. The event started at 8:00 a.m. and ended at 9:00 a.m., with a total incident. The v/Ic ratio at the incident location was 1.44 , resulting in a queue spillback to the upstream signal and capacity constraints at the intersection during portions of the green times of the feeder links to the incident link. This case study demonstrates the use of the developed delay estimation methodology to decide on a special signal timing plan to reduce the spillback impacts. 
To reduce the spillback impacts, the special signal timing plan can be developed by: 1) increasing the green time at the downstream intersection to eliminate backup from the downstream intersection to the incident location, which can further reduce the available capacity at the incident location, and 2) the upstream intersection green and cycle length should be modified to limit the amount of traffic leaving the upstream in each cycle to a level that does not cause spillbacks that constrain the amount of traffic that can leave the upstream stop line in a cycle. However, it was determined from the case study incident that the downstream intersection effective green to capacity $(\mathrm{g} / \mathrm{C})$ ratio is 0.65 , and the incident occurred 0.25 mile from the downstream signal.

Applying the downstream intersection models in Table 1 indicates that for such parameters, there is no interaction between the queue length from the downstream signal and the operations at the incident condition, and thus the incident capacity is not affected by the queues from the downstream intersection. For this reason, no changes are required for downstream signal control timing. However, when applying the models in Table 1, the results indicate a reduction in throughput of the upstream signal due to the incident. Thus, a special signal plan was designed to eliminate the constrained green time, in which traffic from feeder links are blocked by queues from the incident link. The adjustment to the signal timing was made based on the upstream intersection throughput model developed in this study, and the impacts of the adjusted timing were evaluated using VISSIM simulation. Also, VISSIM results were compared with the proposed delay calculation method utilizing the HCM procedure implemented in the ITS. The adjustment to the green made in this study required an estimation of the unconstrained green time for upstream movements. The remaining green will be constrained by the queue spillback. Thus, providing green times equal to the unconstrained green will minimize the lost green due to the spillback. The unconstrained green time is calculated based on the saturation flow rate provided in Table 2.

Table 2. Upstream Signal Maximum Throughput for the Test Scenarios

\begin{tabular}{|c|c|c|c|c|c|c|}
\hline $\begin{array}{l}\text { Time } \\
\text { Stamp } \\
\text { (min }\end{array}$ & $\begin{array}{l}\text { Scenario } 1 \\
\text { Upstream } \\
\text { Node } \\
\text { Throughput } \\
\text { (veh/15min) }\end{array}$ & $\begin{array}{l}\text { Scenario } 2 \\
\text { Upstream } \\
\text { Node } \\
\text { Throughput } \\
\text { (veh/15min }\end{array}$ & $\begin{array}{l}\text { Scenario } 3 \\
\text { Upstream } \\
\text { Node } \\
\text { Throughput } \\
\text { (veh/15 min }\end{array}$ & $\begin{array}{l}\text { Scenario } 4 \\
\text { Upstream } \\
\text { Node } \\
\text { Throughput } \\
\text { (veh/15min) }\end{array}$ & $\begin{array}{l}\text { Scenario } 4 \\
\text { Incident } \\
\text { Location } \\
\text { Throughput } \\
\text { (veh/15min) }\end{array}$ & $\begin{array}{l}\text { Scenario } 5 \\
\text { Upstream } \\
\text { Node } \\
\text { Throughput } \\
\text { (veh/15min) }\end{array}$ \\
\hline 970 & 158 & 158 & 158 & 158 & 158 & 158 \\
\hline 985 & 688 & 688 & 688 & 688 & 688 & 688 \\
\hline 1000 & 689 & 647 & 500 & 474 & 474 & 427 \\
\hline 1015 & 688 & 500 & 500 & 474 & 474 & 427 \\
\hline 1030 & 690 & 500 & 768 & 768 & 746 & 760 \\
\hline 1045 & 689 & 689 & 877 & 878 & 877 & 878 \\
\hline 1060 & 688 & 688 & 878 & 877 & 878 & 877 \\
\hline 1075 & 689 & 689 & 695 & 696 & 688 & 696 \\
\hline 1090 & 687 & 687 & 675 & 675 & 675 & 675 \\
\hline 1105 & 688 & 675 & 675 & 676 & 676 & 676 \\
\hline 1120 & 689 & 689 & 642 & 674 & 675 & 674 \\
\hline
\end{tabular}

Table 3 shows that both VISSIM and the HCM-based methods developed in this study and applied in ITS estimated a reduction in delay due to the updated signal timing during incidents. The HCS-based method estimated a reduction in delay resulting from the new signal timing plan to be around 3,404 vehicle-hours, whereas the VISSIM shows that the new signal 
timing saving in delay is 4,008 vehicle-hours. This confirms that the developed method and VISSIM estimation of the benefits are consistent.

Table 3 Network Delay Saving (Vehicle-hrs) due to Upstream Signal Timing Plan Adjustment During the Incident Condition in VISSIM and the Proposed Analytical

Model

\begin{tabular}{|c|c|c|c|c|}
\hline \multicolumn{5}{|c|}{ VISSIM Models } \\
\hline Scenario & \multicolumn{2}{|c|}{$\begin{array}{c}\begin{array}{c}\text { Network Total Delay } \\
\text { (veh-hrs) }\end{array} \\
\end{array}$} & \multicolumn{2}{|c|}{$\begin{array}{c}\text { SignalAdjustmentSavingDelay } \\
\text { (veh-hrs) }\end{array}$} \\
\hline $\begin{array}{l}\text { Incident without } \\
\text { Signal Adjustment }\end{array}$ & \multicolumn{2}{|c|}{10703} & \multirow{2}{*}{\multicolumn{2}{|c|}{4008}} \\
\hline $\begin{array}{l}\text { Incident with } \\
\text { Signal Adjustment }\end{array}$ & \multicolumn{2}{|c|}{6664} & & \\
\hline \multicolumn{5}{|c|}{ ProposedMethodCombination of Queuing and HCM Equations } \\
\hline Scenario & $\begin{array}{c}\text { Upstream } \\
\text { Signal Delay } \\
\text { (HCM } \\
\text { Equations) } \\
\text { (veh-hrs) }\end{array}$ & $\begin{array}{c}\text { Queuing } \\
\text { Analysis } \\
\text { Delay } \\
\text { (veh-hrs }\end{array}$ & $\begin{array}{c}\text { Total } \\
\text { Delay } \\
\text { (veh-hrs) }\end{array}$ & $\begin{array}{c}\text { Signal } \\
\text { Adjustment } \\
\text { Saving Delay } \\
\text { (veh-hrs) }\end{array}$ \\
\hline $\begin{array}{l}\text { Signal Adjustment } \\
\text { Saving Delay } \\
\text { (veh-hrs) }\end{array}$ & 7008 & 2678 & 9726 & \multirow[t]{2}{*}{3404} \\
\hline $\begin{array}{l}\text { Incident with Signal } \\
\text { Adjustment }\end{array}$ & 5325 & 877 & 6312 & \\
\hline
\end{tabular}

\section{CONCLUSION}

The estimation of incident and incident management strategy impacts on urban street performance is important to a successful planning for operations and operations of active transportation management strategies. This chapter described the development and application of a new model to estimate the impacts of incidents and incident management strategies on urban street facilities. The developed capacity reduction models were used to estimate delay due to an urban street incident. The delay was calculated as a combination of the delay due to queuing on the incident link and the increase in upstream intersection control delays due the reduction in maximum throughputs resulting from queue spillback to the upstream intersection. A comparison with microscopic simulation modeling results showed that the delay estimated using the combination of the increase in control delay based on the reduction in capacity estimated by the developed models and deterministic queuing at the incident location produced better results than using the deterministic queuing procedure by itself for estimating delays. The developed method was successfully incorporated in a data analytic tool to support agency operation decisions and is demonstrated to be able to support agency assessment of the effectiveness of incident management and associated signal control strategies. The developed method to estimate urban street incident impacts was then implemented as part of the multi-resolution modeling to refine the DTA modeling and as an input to the highway capacity manual-based modeling of incident and incident responsive management 
impacts. To supplement the DTA modeling for this purpose, additional regression models were developed to estimate diversion due to urban street incidents. These regression models were combined with the DTA model to estimate the volumes at the incident location and alternative routes. The produced volumes during the incident were then used as inputs to microscopic simulation for more detailed analysis and to demonstrate the benefits of special signal plans during incident conditions.

\section{REFERENCIAS}

Aghdashi B, Khazraeian S, Trask J, Hadi M, Rouphail N, editors. Incorporating Adaptive (Traffic Responsive) Ramp Metering in the Highway Capacity Manual Context. Proceedings of the 96th Annual Meeting of the Transportation Research Board; 2017.

Khazraeian S, Hadi M, Xiao Y. Assessment of the Benefits of Queue Warning in a Connected Vehicle Environment based on Surrogate Safety Measures. Proceedings of the 96th Annual Meeting of the Transportation Research Board; Washington2017.

Hadi M, Sinha P, Wang A. Modeling reductions in freeway capacity due to incidents in microscopic simulation models. Transportation research record. 2007;1999(1):62-8.

Abdel-Rahim, A., A. Krings and M. Dixon (2011). Integrating Clarus Data in Traffic Signal System Operation: A Survivable Real-time Weather-responsive System.

Abdel-Rahim, A. S., W. C. Taylor and A. Bangia (1998). Analysis of Corridor Delay Under

Scats Control. ITS America 8th Annual Meeting and Exposition: Transportation Technology for Tomorrow: Conference Proceedings.

Abdi, A., A. Mehara, S. Monajjem, E. Sadeghvaziri (2014). Simulation Modeling of Dynamic Response of Vehicles to Different Types of Speed Control Humps. American

Society of Civil Engineers (ASCE) T\&DI Congress 2014: pp. 533-542

AG, P. P. T. V. (2007). VISSIM version 5.0 User Manual.Karlsruhe Germany. Agbolosu-Amison, S., A. Sadek and W. ElDessouki (2004). "Inclement Weather And Traffic Flow At Signalized Intersections: Case Study from Northern New England."

Transportation Research Record: Journal of the Transportation Research Board(1867): 163-171.

Agbolosu-Amison, S., A. Sadek and B. Henry (2005). Factors Affecting Benefits of Implementing Special Signal Timing Plans for Inclement Weather Conditions.

Transportation Research Record: Journal of the Transportation Research Board(1925): 146-155.

Aghdashi, B., S. Khazraeian, J. Trask, M. Hadi, N. Rouphail, "Incorporating Adaptive (Traffic Responsive) Ramp Metering in the Highway Capacity Manual Context",

Proceedings of the 96th Annual Meeting of the Transportation Research Board, Washington, D.C., January 2017.

Ahmad, I., Suksawang, N., Sobhan, K., Corven, J., Sayyafi, E. A., Pant, S., \& Martinez, F.

(2015). Develop Epoxy Grout Pourback Guidance and Test Methods to Eliminate Thermal/Shrinkage Cracking at Post-Tensioning Anchorages: Phase II. Transport Research International Documentation (TRID), Florida Department of Transportation.

Al-Kaisy, A. and Z. Freedman (2006). Weather-Responsive Signal Timing: Practical Board(1978): 49-60.Guidelines. Transportation Research Record: Journal of the Transportation Research 
Balke, K. and D. Gopalakrishna (2013). Utah DOT Weather Responsive Traffic Signal

Timing.

Banerjee and T. Frances (2001). Preliminary Evaluation Study of Adaptive Traffic Control System. ITS Benefits Database Entry.

Baqersad, M., Mohammadafzali, M., Choubane, B., Holzschuher, C., Hamedi, A. and Ali, H. (2017). "Precision Assessment of the Florida Texture Meter in Hot Mix Asphalt." ASCE's Journal of Transportation Engineering, Part B: Pavements, in press.

Baqersad, M., Hamedi, A., Mohammadafzali, M. and Ali, H., 2017. Asphalt Mixture Segregation Detection: Digital Image Processing Approach. Advances in Materials Science and Engineering, 2017.

Carrion, C. and D. Levinson (2012). Value of travel time reliability: A review of current

evidence.Transportation research part A: policy and practice 46(4): 720-741.

Carson, J. L. (2009). Traffic Incident Management Resource Management.

Chang, G. L. and S. Rochon (2006). Performance Evaluation of CHART-the Real Time Incident Management System in Year 2006. Maryland Department of Transportation.

Chiu, Y.-C. and B. Bustillos (2009). A Gap Function Vehicle-Based Solution Procedure For Consistent and Robust Simulation-Based Dynamic Traffic Assignment. Transportation Research Board 88th Annual Meeting.

J. R. Sturdevant and T. M. Brennan (2014). Performance Measures for Traffic Signal Systems: An Outcome-Oriented Approach.

Dia, H. and N. Cottman (2006). Evaluation of Arterial Incident Management Impacts Using Traffic Simulation. Intelligent Transport Systems, IEE Proceedings, IET.

Dong, J. and H. Mahmassani (2009). Flow Breakdown and Travel Time Reliability.Transportation Research Record: Journal of the Transportation Research Board (2124): 203-212.

EconomicDevelopmentResearchGroup, I., I. Cambridge Systematics, I. International, T. T. A. M. T. Institute and I. Weris (2013). Development of Tools for Assessing Wider Economic Benefits of Transportation.

FDOT (2006). Annual Report Smart Sunguide TMC. software for distributed systems. IECON 02 [Industrial Electronics Society, IEEE 2002 28th Annual Conference of the], IEEE.

Gillam, W. and R. Wilhill (1992). UTC and Inclement Weather Conditions. Road Traffic Monitoring, 1992 (IEE Conf. Pub. 355), IET.

Glassco, R. A., A. Proper, V. Shah and K. Wunderlich (1997). Studies of Potential Intelligent Transportation Systems Benefits Using Traffic Simulation Modeling-Volume to Evaluate the Benefits and Costs of Advanced Traffic Management Components By.Hadi, M., P. Sinha and A. Wang (2007). Modeling Reductions in Freeway Capacity Due To Incidents In Microscopic Simulation Models. Transportation Research Record: Journal of the Transportation Research Board(1999): 62-68.

Hadi,M., Y. Xiao, H. Ozen and P. Alvarez (2008). Evaluation Tools to Support ITS Planning Process: Development of a Sketch Planning Tool in FSUTMS/Cube Environment.

Jones, S. L., A. J. Sullivan, N. Cheekoti, M. D. Anderson and D. Malave (2004). Traffic Simulation Software Comparison Study, University Transportation Center for Alabama. 
Khazraeian, S., M. Hadi, Y. Xiao, “Assessment of the Benefits of Queue Warning in a Connected Vehicle Environment based on Surrogate Safety Measures," Proceedings of the96th AnnualMeeting of the Transportation Research Board, Washington, D.C., January 2017

Lardoux, J., R. Martinez, C. White, N. Gross, N. Patel and R. Meyer (2014). Adaptive Traffic Signal Control for Tarrytown Road in White Plains, New York.

Mahmassani, H. S., J. Kim, Y. Chen, Y. Stogios, A. Brijmohan and P. Vovsha (2014). Incorporating Reliability Performance Measures into Operations and Planning Modeling Tools, Transportation Research Board.

Massahi, A., Hadi, M., Adriana Cutillo, M., and Xiao, Y., (2017). Estimating the Capacity Impacts of Urban Street Incidents. Transportation Research Record (TRR) Journal, Journal of the Transportation Research Board.

Rojas, M., E. Sadeghvaziri, X. Jin (2016). A Comprehensive Review of Travel Behavior and Mobility Pattern Studies Using Mobile Phone Data. Transportation Research Record: Journal of the Transportation Research Board, No. 2563, Washington, D.C., 2016, pp. 71-79 